\title{
Análise da Comunicação de Crianças com Paralisia Cerebral sem Oralidade Durante Atividade com Jogos Digitais
}

\section{Analysis of the Communication of Nonspeaking Children with Cerebral Palsy During Activities with Digital Games}

\begin{abstract}
Resumo: Na perspectiva da Tecnologia Assistiva e de sua aplicação no contexto da Comunicação Alternativa, os jogos digitais podem ser produzidos e aplicados em atividades lúdicas junto às crianças com transtorno severo da fala com o intuito de ampliar a comunicação. Este trabalho tem por objetivo analisar a frequência de ocorrência das diferentes formas de comunicação de crianças sem oralidade durante atividades com jogos digitais. Participaram desta pesquisa quatro crianças com deficiências múltiplas, decorrentes de Paralisia Cerebral, sendo três do sexo masculino e uma do sexo feminino com idades entre 7 e 12 anos. Todas as crianças apresentaram severos distúrbios na comunicação oral. Três jogos digitais foram desenvolvidos para essa população: Segurança Alimentar, Segurança Pública e Cidade Sustentável. As atividades com os jogos ocorreram em 5 sessões, com duração de aproximadamente 20 minutos com cada criança. A partir da análise das filmagens, por meio do registro de observação, foi possível identificar a ocorrência de cinco categorias de comunicação, na seguinte ordem decrescente: Vocal e não verbal, Não verbal, Vocal com ajuda, Não verbal com ajuda e Vocal. Discute-se a importância da análise das diferentes possibilidades de expressão dessas crianças para o planejamento de intervenções mais eficazes na área da Comunicação Alternativa.

Palavras-chave: Paralisia Cerebral. Jogos Digitais. Comunicação Alternativa. Tecnologia Assistiva.
\end{abstract}

\begin{abstract}
According to the assistive technology approach to help people who are physically impaired and its application in the context of Alternative Communication, digital games can be produced and applied in playful activities with children with severe speech disorder in order to expand communication. This paper aims to analyze the frequency of occurrence of different forms of communication in nonspeaking children during activities with digital games. Participated in this study were four children with multiple disabilities, whose limitations were due to cerebral palsy, three male and one female aged between 7 and 12 years. All children had severe oral communication disability. Three digital games were developed for this population: Food Safety, Public Safety and Sustainable City. The activities with the three digital games occurred in five sessions, lasting about $20 \mathrm{mi}-$ nutes with each child. From the analysis of the footage, by recording the observation, it was possible to identify the occurrence of five categories of communication, in decreasing order: Vocal and non-verbal, no verbal, vocal with help, no help with verbal and vocal. It discusses the importance of examining the different possibilities of expression of these children to plan more effective interventions in the area of Alternative Communication.

Keywords: Cerebral Palsy. Digital Games. Alternative Communication. Assistive Technology.
\end{abstract}

FERREIRA, Maria Inês Jesus. et al. Análise da Comunicação de Crianças com Paralisia Cerebral sem Oralidade Durante Atividade com Jogos Digitais. I nformática na Educação: teoria e prática, Porto Alegre, v. 15, n. 2, p. 215-227, jul./dez. 2012.

\author{
Maria Inês Jesus Ferreira \\ Camila de Sousa Pereira-Guizzo \\ Xisto Lucas Travassos \\ Lynn Rosalina Gama Alves \\ Renelson Ribeiro Sampaio \\ Faculdade de Tecnologia SENAI CIMATEC
}

\section{Introdução}

A comunicação é importante e necessária para a interação social. É por meio da comunicação que o indivíduo interage com os outros e troca informações com o ambiente sociocultural. Contudo, uma das barreiras para o processo de comunicação é a

\footnotetext{
${ }^{1}$ Este artigo é parte da Dissertação de Mestrado realizada pela primeira autora, sob a orientação da segunda autora e a coorientação do quinto autor. Esta pesquisa foi desenvolvida por meio da participação no projeto Desenvolvimento de Ferramentas de Entretenimento Acessível a Pessoas com Necessidades Especiais na Plataforma de Comunicação Aumentativa Alternativa, coordenado pelo terceiro autor e com a colaboração da quarta autora. Este projeto é fomentado pela FAPESB através do Termo de Outorga TSC 0039/2009.
} 
ausência da fala para expressar-se oralmente com o meio (SAMESHIMA, 2006). A dificuldade de comunicação pode ser uma sequela presente junto às pessoas com Paralisia Cerebral, dentre outras limitações, conforme a lesão cerebral. Por isso, profissionais e pesquisadores da área de Educação Especial vem se preocupando com a identificação e o desenvolvimento da comunicação dessas crianças (ALMEIDA; PIZA; LAMÔNICA, 2005, DELIBERATO; GONÇALVES; MACEDO, 2009, NUNES, 2003, ZANGARI, 1994). Segundo Sameshima e Deliberato (2009), a preocupação remete principalmente à necessidade de identificar as diversas possibilidades de comunicação dos indivíduos com deficiência sem oralidade, de modo a contribuir para a seleção de estratégias e de promoção do desenvolvimento das trocas comunicativas e do processo de interação social das pessoas com dificuldades específicas na fala.

Na comunicação interpessoal, Del Prette e Del Prette (2001) discutem que o conteúdo de uma mensagem pode ser transmitido verbalmente, por meio da fala ou da escrita, somando-se ainda ao componente não verbal (gestos, postura corporal, movimentos com a cabeça, expressão facial) e paralinguístico (tom de voz, entonação, velocidade da fala). No caso de indivíduos sem oralidade, a sua comunicação com o meio pode ser estabelecida por meio da expressão facial, uso de gestos, movimentos com a cabeça e vocalizações. Conforme Millikin (1996, apud SAMESHIMA, 2006) uma mensagem pode ser classificada como verbal (apresenta um código linguístico), não verbal (transmite mensagens sem empregar um código linguístico estruturado), vocal (produção de som) e não vocal ( não envolve produção de som).
Assim, a literatura tem revelado as diferentes formas de comunicação de crianças e adolescentes com problemas de comunicação ou sem oralidade (AGUIAR et al., 2010, FERM; AHLSÉN; BJORCK-AKESSON, 2005, MCLEAN; BRADY; MCLEAN, 1996, NUNES, 2003, WALTER, 2006, ZANGARI, 1994). Por exemplo, Deliberato (2009) descreveu as habilidades expressivas orais de um aluno com Paralisia Cerebral de 11 anos, durante a implementação de um programa na área de comunicação suplementar e alternativa. A filmagem de 12 sessões permitiu identificar as categorias de análises: expressão verbal; não verbal; e expressão verbal concomitante a expressão não verbal. A expressão não verbal foi a categoria mais frequente. Em outro estudo, Sameshima e Deliberato (2009) identificaram em três adolescentes com Paralisia Cerebral sem oralidade (idade entre 13 e 16 anos), durante atividades de jogos de mesa, as seguintes habilidades expressivas: verbal sem ajuda/vocal; verbal com ajuda/não vocal; não verbal/ vocal; não verbal/não vocal; não verbal/não vocal + não verbal/vocal; verbal sem ajuda/ vocal + não verbal/vocal; não verbal/vocal + verbal com ajuda/não vocal e não verbal/não vocal + verbal com ajuda/não vocal. As categorias mais utilizadas pelos adolescentes para a comunicação foram: não verbal/não vocal; verbal com ajuda/não vocal e não verbal/não vocal + não verbal/vocal.

Esses estudos (DELIBERATO, 2009, SAMESHIMA; DELIBERATO, 2009), bem como outras investigações (ALMEIDA; PIZA; LAMÔNICA, 2005, NUNES, 2003) chamam a atenção dos profissionais para as diferentes formas de comunicação das pessoas com Paralisia Cerebral sem oralidade, mostrando a importância do levantamento de necessida- 
des e da seleção de estratégias mais adequadas para a ampliação da comunicação. Nesse sentido, uma temática que vem crescendo consideravelmente nos últimos anos na pesquisa e na prática é a Comunicação Alternativa (DELIBERATO; GONÇALVES; MACEDO, 2009). Segundo Nunes (2003), a Comunicação Alternativa pode ser compreendida como as diferentes formas de comunicação (uso de gestos, expressões faciais e corporais, símbolos gráficos) que possam estabelecer a comunicação face a face de indivíduos incapazes de usar a linguagem oral.

Uma área que muito utiliza a Comunicação Alternativa é a Tecnologia Assistiva. Por meio do desenvolvimento de recursos como pranchas de comunicação com simbologias gráficas ou vocalizadores, computadores com softwares específicos, dentre outras ferramentas, a Tecnologia Assistiva contribui para a promoção da funcionalidade da comunicação de pessoas com transtornos severos de expressão oral, possibilitando a ampliação da aprendizagem e da interação social dessa população (BERSCH, 2009, BROWNING, 2003).

Nessa perspectiva da Tecnologia Assistiva, uma das possibilidades para favorecer a comunicação é o jogo digital. Os jogos digitais podem ser utilizados por todos os indivíduos, inclusive por aqueles que apresentam algum tipo de deficiência. Nesse caso, os jogos digitais podem ser desenvolvidos de acordo com as necessidades especiais da criança, adaptando-se a contextos variados e aplicados a diferentes objetivos de intervenção. Com o apoio da tecnologia na promoção da funcionalidade da comunicação, os jogos digitais podem atuar como espaço motivador e desafiador para o desenvolvimento das habilidades cognitivas e sociais.
De acordo com Vygotsky (1984), os jogos propiciam o desenvolvimento da linguagem, do pensamento e da atenção. O lúdico influencia na aprendizagem da criança, ensinando-a a agir em uma determinada situação e estimulando sua capacidade de discernimento e de solução de problemas. Para Huizinga (2001), o jogo pode ser definido como uma atividade lúdica muito mais ampla que um fenômeno físico ou reflexo psicológico, apresentando ainda três características: (1) é uma atividade livre e voluntária, jamais imposta; (2) pode funcionar como escape da vida cotidiana para um mundo imaginário; (3) pode criar ordem e ele próprio ser ordem. Dessa forma, os jogos nos seus diferentes suportes atuam na Zona de Desenvolvimento Proximal (VYGOTSKY, 2009), mediando a construção de distintos conceitos, promovendo o desenvolvimento das funções cognitivas, comunicacionais, afetivas e motoras. O mediador que interage com a criança intervém, provocando a emergência de processos de internalização que se estruturam tanto em nível inter como intrapsiquico, permitindo a elaboração e reelaboração destes processos que emergem do coletivo para o individual.

Diante dessas considerações, percebe-se a importância do jogo digital para a promoção da comunicação e da interação social entre as pessoas com deficiência, bem como a necessidade de ampliar o conhecimento científico nessa temática. É dentro desse contexto que o presente trabalho teve por objetivo analisar a frequência de ocorrência da comunicação de crianças com Paralisia Cerebral sem oralidade durante as atividades com jogos digitais. 


\section{Método}

A pesquisa seguiu os preceitos da Resolução 196/1996 do Conselho Nacional de Saúde em relação às Diretrizes e Normas Regulamentadoras de Pesquisas Envolvendo Seres Humanos e foi aprovada pelo Comitê de Ética em Pesquisa da Secretaria da Saúde do Estado da Bahia (Parecer 368/2009). Além da autorização da instituição, os pais das crianças assinaram o Termo de Consentimento Livre e Esclarecido permitindo a participação dos filhos no presente estudo.

\subsection{Participantes}

Os critérios de inclusão da amostra foram: (a) possuir Paralisia Cerebral; (b) sem oralidade; (c) faixa etária entre 7 e 12 anos; e (d) consentimento dos pais. Assim, o estudo contou com a participação de quatro crianças com deficiências múltiplas, decorrentes da Paralisia Cerebral. A faixa etária dos participantes era entre 7 e 12 anos, sendo três crianças do sexo masculino e uma do sexo feminino. A Tabela 1 apresenta as principais características dessas crianças.

TABELA 1 - Características dos Participantes do Estudo

\begin{tabular}{|c|c|c|c|}
\hline $\begin{array}{c}\text { Partici- } \\
\text { pante }\end{array}$ & $\begin{array}{c}\text { I da- } \\
\text { de }\end{array}$ & Sexo & Características \\
\hline Paulo & 7 & $\begin{array}{c}\text { Mascu- } \\
\text { lino }\end{array}$ & $\begin{array}{c}\text { Paralisia Cerebral, sem } \\
\text { oralidade, comprometimento } \\
\text { auditivo severo (usa aparelho } \\
\text { auditivo), comprometimento } \\
\text { motor (tetraplégico) e com- } \\
\text { prometimento visual modera- } \\
\text { do (usa lentes corretivas). }\end{array}$ \\
\hline Carla & 8 & $\begin{array}{c}\text { Femi- } \\
\text { nino }\end{array}$ & $\begin{array}{c}\text { Paralisia Cerebral, sem } \\
\text { oralidade, comprometimento } \\
\text { auditivo leve e comprometi- } \\
\text { mento motor leve. }\end{array}$ \\
\hline
\end{tabular}

\begin{tabular}{|c|c|c|c|}
\hline Everaldo & 10 & $\begin{array}{c}\text { Mascu- } \\
\text { lino }\end{array}$ & $\begin{array}{c}\text { Paralisia Cerebral, sem } \\
\text { oralidade, comprometimento } \\
\text { auditivo moderado, com- } \\
\text { prometimento visual leve } \\
\text { e comprometimento motor } \\
\text { moderado. }\end{array}$ \\
\hline Danilo & 12 & $\begin{array}{c}\text { Mascu- } \\
\text { lino }\end{array}$ & $\begin{array}{c}\text { Paralisia Cerebral, sem } \\
\text { oralidade, comprometimento } \\
\text { auditivo moderado e compro- } \\
\text { metimento motor moderado } \\
\text { nos membros superiores e } \\
\text { inferiores. }\end{array}$ \\
\hline
\end{tabular}

Nota. Os nomes são fictícios.

FONTE: Elaborado pelos próprios autores.

Como mostra a Tabela 1, todas as crianças tinham distúrbio severo da comunicação oral, ou seja, sem oralidade. Além disso, a classe econômica dos participantes variou entre B1 e $D$, segundo o instrumento de domínio público Critério de Classificação Econômica Brasil (ASSOCIAÇÃO BRASILEIRA DE EMPRESAS DE PESQUISA, 2003).

\subsection{Espaço Empírico}

A pesquisa foi realizada em uma instituição pública estadual, localizada no estado da Bahia, que atende pessoas com Paralisia Cerebral e outros transtornos do desenvolvimento. A pesquisa foi conduzida na sala de atendimento fonoaudiológico.

\subsection{I nstrumentos}

Registro de Observação. Com base nos estudos de Deliberato (2009) e Sameshima (2006), este registro de observação foi elaborado visando a avaliação da ocorrência dos diferentes tipos de comunicação de crianças 
sem oralidade. Possui cinco categorias que são definidas operacionalmente do seguinte modo: (1) Não verbal - uso de gestos, expressões faciais, movimentos com a cabeça e sorriso; (2) Não verbal com ajuda - utiliza recursos de comunicação alternativa por meio de indicações gestuais; (3) Vocal - emite vocalizações, emissões de vogais e/ou entonação da voz; (4) Vocal com ajuda - emissões de vocalizações concomitantes ao uso de recursos de comunicação alternativa; (5) Vocal e não verbal - uso de vocalizações em conjunto com gestos, expressões faciais e sorriso.

Diário de Campo. Caderno de registro, presente em todas as sessões, para descrever a comunicação das crianças durante as atividades com os jogos digitais, complementando as cenas captadas pela filmadora.

Jogos Digitais. Três jogos digitais - caracterizados como casuais, com narrativas simples, exigindo do jogador respostas para um problema de cada vez - foram desenvolvidos por meio do projeto Desenvolvimento de Ferramentas de Entretenimento Acessível a Pessoas com Necessidades Especiais na Plataforma de Comunicação Aumentativa Alternativa, coordenado pelo terceiro autor do presente artigo. Antes do desenvolvimento dos jogos, foi realizada uma visita à instituição para verificar a deficiência foco do estudo. Partindo desta definição (Paralisia Cerebral), realizouse o levantamento junto ao prontuário e aos profissionais que acompanhavam essas crianças na instituição para identificação de suas necessidades e limitações. Como todas as crianças participantes da pesquisa possuíam perda auditiva (severa, leve e moderada), foi acordado que os jogos não teriam efeitos sonoros. A partir desse diagnóstico, a equipe da área de microeletrônica do SENAI
CIMATEC desenvolveu os jogos. Os três jogos digitais criados e utilizados para a intervenção possuem as seguintes temáticas: Cidade Sustentável, Segurança Pública e Segurança Alimentar.

Os jogos digitais foram executados em um PDA - Personal Digital Assistant, que opera um sistema operacional Linux de código aberto e, portanto, gratuito. Este PDA usa um processador ARM 9 que possui baixo poder computacional, se comparado aos tablets ou aos smartphones modernos. Dentre as vantagens da utilização do sistema operacional Linux Embarcado, frente a outros sistemas operacionais, estão: a licença livre e gratuita para uso e a possibilidade de redistribuição e modificação do código fonte. O acesso aos jogos ocorre por meio de um leve toque sobre o ícone diretamente na tela, uma vez que sobre a tela principal, há uma tela touchscreen (tela sensível ao toque). A linguagem de programação utilizada é o $\mathrm{C}++$ com a biblioteca gráfica DirectFB. A biblioteca DirectFB provê aceleração gráfica, tratamento de eventos oriundos de dispositivos de entrada (como o teclado e o mouse) e sistema de janelas (DirectFB, 2011). Baseado nestas plataformas livres e comumente utilizadas por programadores foi desenvolvido o software de comunicação para distribuição livre para aprimoramento.

O fluxograma do jogo é uma explicação visual de como os elementos do jogo e suas propriedades interagem. Representa os objetos, as propriedades e as ações presentes. Para demonstrar essa situação, foi elaborado o fluxograma, onde podem ser verificadas as ações que devem ser executadas na interação das crianças e os jogos digitais. A Figura 1 ilustra o fluxograma dos jogos. 


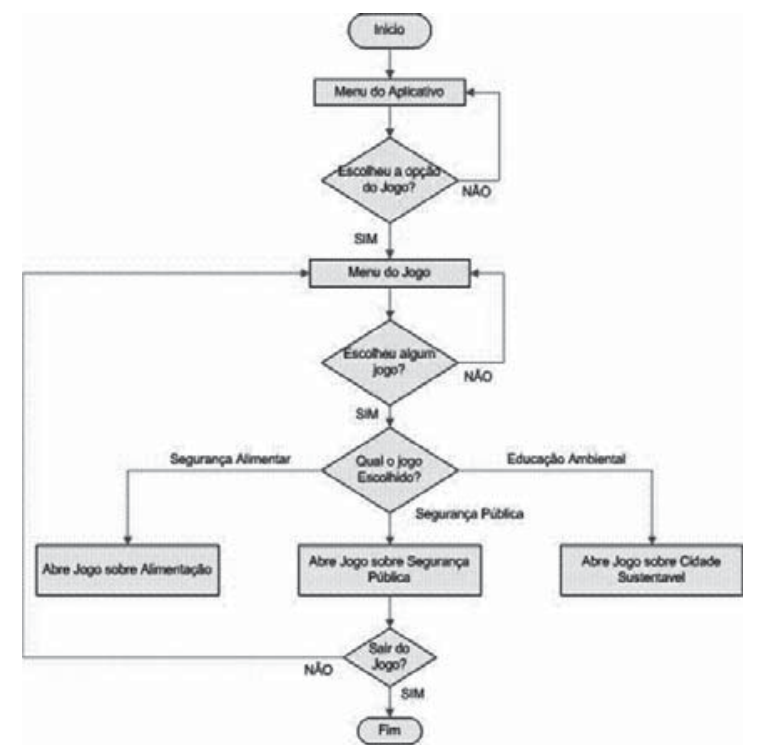

FIGURA 1 - Fluxograma Menu do Software e Jogos Digitais

FONTE: Elaborado pelos próprios autores.

A Figura 1 revela a interação da criança com os jogos, podendo observar que o jogador vai para o menu do Dispositivo eletrônico portátil. O jogador clica no ícone que dá acesso ao menu, podendo assim escolher o jogo. A descrição de cada jogo é apresentada a seguir.

Jogo Segurança Alimentar. A proposição é o jogo da alimentação, formado por uma tela, com três pratos e várias gravuras de alimentos saudáveis. Este jogo visa sensibilizar as crianças para a importância de uma alimentação saudável e uma dieta balanceada, atentando para a diversidade de alimentos: carboidratos, frutas, verduras, proteínas e bebidas. Cada grupo de alimentos possui uma cor que preenche o pano de fundo da imagem de cada alimento. A criança deve colocar os alimentos nos espaços adequados, associando a cor do pano de fundo que envolve o alimento e o espaço adequado com a mesma cor. As figuras devem apresentar a mesma estratégia do PCS - Picture Communication Symbols, ou seja, apresentar-se também por escrito. Exemplo: imagem do cereal arroz e nome produto arroz logo acima. O fundo das imagens tem cor padrão, ou seja, única. Cada vez que entrar no jogo, o jogador visualiza os alimentos em uma sequência diferente. Ao concluir cada fase, aparece um sinal de positivo indicando que venceu. Além disto, há a opção de botão à ação seguinte (sair do jogo). Para jogar, a criança deve arrastar os alimentos até os respectivos pratos. Ao chegar ao local adequado à cor do fundo da gravura fica igual a do compartimento adequado, colocando o ambiente no local errado ele não fica, retorna automaticamente para a barra rolante.

Jogo Cidade Sustentável. O jogador deve realizar uma coleta seletiva retirando sujeiras que aparecem no rio e colocar no recipiente correspondente a cada tipo de matéria. Cada tipo de lixo (papel, vidro, plástico e metal) deve ser posicionado na cesta adequada. Este jogo apresenta três cenários que demonstram as condições do ambiente (poluído, mais ou menos poluído e despoluído). Ao iniciar a fase, a criança encontra um ambiente limpo, responsável pela conservação deste ambiente. A tela é composta de prédios, nuvens, rio, vários tipos de lixos (metais, papéis, vidros e plásticos). Aparece no alto da tela uma barra de rolagem que indica o estado do ambiente, conforme a realização da coleta do lixo pela criança. Quando o jogo tem início, os lixos começam a aparecer no rio e a criança deve fazer a coleta, utilizando os vasilhames correspondentes a cada lixo. 
A criança pode ainda relacionar o lixo com a cor do vasilhame. Caso não consiga colocar o lixo no tempo adequado, o lixo passa, provocando a poluição do ambiente. Se conseguir colocar todos os lixos nos locais corretos, a criança consegue manter o ambiente despoluído e vence o jogo. A barra que aparece no centro superior da tela fica toda verde e aparece o sinal de positivo indicando que a criança venceu o jogo.

Jogo Segurança Pública. O jogador deve solucionar um quebra-cabeça. Durante a interação, o jogador pode ser desafiado a montar quatro, nove ou dezesseis peças. O desafio é formar as imagens (quadros) indicando posturas adequadas para preservar o ambiente. No início do jogo é apresentada uma imagem com comportamentos ambientalmente incorretos. Ao montar o quebra-cabeça a criança forma uma imagem na qual aparece uma situação ambientalmente correta e segura. $\mathrm{Na}$ tela 1, aparece rapidamente uma imagem de uma cidade suja, lixo pelo chão, pedestre andando pelo meio da rua, carro parado na faixa do pedestre. Na tela 2, aparece uma criança pensando num ambiente limpo e organizado. $\mathrm{Na}$ tela 3, a criança aparece triste. Na tela 4, aparece, como pano de fundo, uma imagem de uma ambiente organizado e sobre esta imagem, no centro, três quadrados cada um indicando uma quantidade de peças (quatro, nove e dezesseis). Ao clicar em um destes quadrados aparece a tela $5 \mathrm{com}$ a imagem padrão na parte superior do lado esquerdo de um ambiente organizado, igual a imaginada pela criança. No restante do espaço aparece um quadro com esta imagem em forma de quebra-cabeça, onde o aluno deve armar, utilizando como modelo a imagem que aparece no canto esquerdo do lado superior da tela.
Para girar as peças, ele deve clicar no ícone girar e na peça e assim sucessivamente, até conseguir montar o quadro, quando aparece o sinal de positivo dizendo que a criança venceu. A criança pode ir para o próximo desafio (número de peças) ou sair deste jogo.

\section{A Mediação}

A pesquisadora construiu uma representação conceitual fundamentada na concepção de Vygotsky, na interação do objeto da pesquisa, na mediação e suas variáveis. É uma representação física ou simbólica de informações reproduzidas dos comportamentos observáveis. Segue representação conceitual de mediação das crianças, durante as sessões.

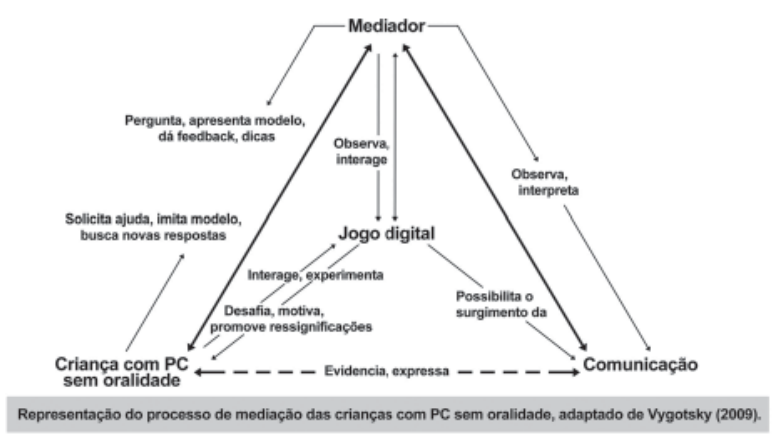

FIGURA 2 - Representação Do Processo De Mediação, Adaptado De Vygotsky (2009)

FONTE: Elaborado pelos próprios autores.

$\mathrm{Na}$ mediação permanecia apenas uma criança, a mediadora (Fonoaudióloga) e a pesquisadora (primeira autora - desempenhando o papel de observadora). Inicialmente, a especialista apresenta a proposta, o 
funcionamento e as regras dos jogos digitais para conhecerem e se familiarizarem com a atividade; orienta a criança através de instruções, questionamentos, dicas e feedback; utiliza exemplos de situações do dia a dia da criança e toda mediação necessária para o desenvolvimento da atividade. A expressão da criança era observada para que a mediadora pudesse intervir. As instruções ocorriam através de figuras, uso da comunicação não verbal e apresentação de modelo. As crianças tinham autonomia de acesso em todas as etapas dos jogos.

A interação com o jogo se dava mediante o toque das crianças na tela do PDA, inicialmente por imitação, posteriormente por tentativa e erro, para finalmente se constituir em um ato planejado. A comunicação não verbal atuou como a linguagem mediadora, na medida em que as crianças buscavam a aprovação das suas interferências e inferências na tela, através do olhar e do gestual da mediadora, contribuindo para formas diferenciadas de comunicação entre sujeito/mediador e para a realização da atividade.

\section{Procedimento de Coleta e Análise dos Dados}

No primeiro momento, foram realizadas observações das crianças e uma entrevista com a fonoaudióloga e equipe de profissionais da instituição para selecionar os sujeitos participantes da amostra e conhecer suas características, necessidades e limitações. Atentos às necessidades comunicacionais e motoras das crianças participantes desta pesquisa, os jogos digitais foram desenvolvi- dos. As atividades com os três jogos digitais ocorreram em cinco sessões, com duração de aproximadamente 20 minutos com cada criança. As atividades com os jogos foram realizadas com as crianças individualmente, conforme agendamento e mediação apresentada anteriormente.

As filmagens foram analisadas por meio do Registro de Observação. O registro das sessões para o Diário de Campo ocorria durante e após as atividades. Os dados coletados foram analisados por meio de frequência absoluta, considerando a ocorrência da comunicação de cada criança durante as atividades, bem como das categorias de comunicação em cada jogo. O índice de concordância das avaliações das filmagens, realizada pela pesquisadora, foi testada em aproximadamente $25 \%$ das situações com duas observadoras externas (IC/A e IC/B). Os resultados do índice de concordância em cada jogo foram satisfatórios: Alimentação - 66,3\% (IC/A) e 63,4\% (IC/B); Cidade Sustentável - 84,5\% (IC/A) e $71,2 \%$ (IC/B); e Segurança Pública - $72,3 \%$ (IC/A) e $80,5 \%$ (IC/B).

\section{Resultados}

As observações permitiram identificar as diferentes formas de comunicação dos participantes durante as atividades com os jogos digitais. A Tabela 2 apresenta a ocorrência das categorias de comunicação com cada criança. 
TABELA 2 - Frequência da Comunicação de Cada Criança Participante do Estudo.

\begin{tabular}{|c|c|c|c|c|}
\hline & Everaldo & Paulo & Carla & Danilo \\
\hline Não verbal & 23 & 20 & 37 & 33 \\
\hline $\begin{array}{c}\text { Não verbal com } \\
\text { ajuda }\end{array}$ & 13 & 11 & 20 & 18 \\
\hline Vocal & 11 & 9 & 17 & 15 \\
\hline Vocal com ajuda & 21 & 20 & 37 & 33 \\
\hline $\begin{array}{c}\text { Vocal e não } \\
\text { verbal }\end{array}$ & 30 & 40 & 76 & 66 \\
\hline Total & 98 & 100 & 187 & 165 \\
\hline
\end{tabular}

Nota. Os nomes são fictícios.

FONTE: Elaborado pelos próprios autores.

Os resultados da Tabela 2 revelam que Carla foi a criança quem mais utilizou as diferentes categorias de comunicação. Por sua vez, a menor frequência de ocorrência das diversas formas de comunicação apareceu com Everaldo.

A partir da análise das filmagens, foi possível identificar também a frequência de ocorrência da comunicação por categorias e por jogos digitais. A Tabela 3 ilustra a frequência dessas categorias em cada jogo digital.

TABELA 3 - Uso das Categorias de Comunicação em Cada J ogo Digital

\begin{tabular}{|c|c|c|c|c|}
\hline \multirow[b]{2}{*}{ Categorias } & \multicolumn{3}{|c|}{ Jogos Digitais } & \multirow[b]{2}{*}{$\begin{array}{l}\text { To- } \\
\text { tal }\end{array}$} \\
\hline & $\begin{array}{c}\text { Segu- } \\
\text { rança } \\
\text { Alimentar }\end{array}$ & $\begin{array}{c}\text { Cidade } \\
\text { Susten- } \\
\text { tável }\end{array}$ & \begin{tabular}{|l|} 
Segu- \\
rança \\
Pública
\end{tabular} & \\
\hline Vocal e não verbal & 90 & 68 & 54 & 212 \\
\hline Não verbal & 44 & 34 & 35 & 113 \\
\hline Vocal com ajuda & 44 & 34 & 33 & 111 \\
\hline $\begin{array}{c}\text { Não verbal com } \\
\text { ajuda }\end{array}$ & 24 & 18 & 20 & 62 \\
\hline Vocal & 20 & 15 & 17 & 52 \\
\hline Total & 222 & 169 & 159 & \\
\hline
\end{tabular}

FONTE: Elaborado pelos próprios autores.
A Tabela 3 mostra a ocorrência de cada categoria de comunicação das crianças durante a realização de cada jogo digital. Observa-se que a categoria mais utilizada pelas crianças foi a Vocal e não verbal. Na sequência surgiram as categorias Não verbal, Vocal com ajuda e Não verbal com ajuda. A categoria menos utilizada pelas crianças foi a Vocal.

Como se vê na Tabela 3, ainda que nos três jogos digitais tenha sido observada a ocorrência dos diferentes tipos de comunicação, foi no jogo Segurança Alimentar que ocorreu maior frequência das categorias analisadas junto às crianças. Na sequência, Cidade Sustentável e, por fim, Segurança Pública.

\section{Discussão}

Este estudo analisou a frequência de ocorrência da comunicação de crianças com deficiências múltiplas, decorrentes de Paralisia Cerebral, e sem oralidade durante as atividades com jogos digitais. A observação da ocorrência da comunicação em atividades com jogos é importante para que os profissionais que trabalham com esta clientela possam ficar atentos às necessidades educacionais da população-alvo, ao estabelecimento dos objetivos da intervenção e ao planejamento das ações, como já apontaram outras investigações (NUNES, 2003, SAMESHIMA; DELIBERATO, 2009).

Os resultados mostraram que as quatro crianças, considerando suas particularidades, estabeleceram formas diferentes de comunicação durante as atividades com os jogos digitais. Esse resultado é coerente com os achados dos estudos de Almeida, Piza e 
Lamônica (2005), Deliberato (2009) e Sameshima e Deliberato (2009) realizados também com crianças com Paralisia Cerebral e transtornos severos na fala.

A categoria de comunicação que surgiu com maior frequência (Vocal e não verbal) sugere que as intervenções nessa área da Comunicação Alternativa devem explorar as várias formas de uma criança se expressar com seu meio. A ausência da fala não significa que o indivíduo seja desprovido de condições para interagir com o ambiente. Cabe ao mediador identificar e potencializar as possibilidades de cada um, favorecendo, por sua vez, o desenvolvimento e a autonomia dessas pessoas.

Os três jogos digitais, previamente desenvolvidos para as crianças, possibilitaram a observação da ocorrência da comunicação entre os participantes do estudo. Além disso, o movimento das mãos e pernas, o brilho nos olhos e o sorriso das crianças expressaram a curiosidade, o entusiasmo e a motivação com a possibilidade de manusear o equipamento e os jogos nele instalados. Isso mostra que de fato a Tecnologia Assistiva pode contribuir para o aprendizado e a ampliação da comunicação de crianças sem oralidade por meio da criação de dispositivos e acessórios computacionais - conforme classificação de AmaralLauand e Mendes (2008) - que atendam à necessidade de sua clientela.

No jogo digital Segurança Alimentar, as crianças manifestaram maior ocorrência da comunicação. Uma hipótese para isso pode ser o fato de tratar-se de um tema que faz parte da rotina dessas crianças. Essa questão também levanta a discussão sobre a importância das atividades considerarem o interesse e a familiariadade dos sujeitos com o tema proposto, como reforçado no estudo de Deliberato (2009), no qual a autora chama a atenção para a importância desse cuidado de seleção de estratégias e temas durante as intervenções na área de Comunicação Alternativa com o intuito de fomentar a conversação de seus usuários.

Analisando a representação conceitual do processo de mediação e as observações realizadas durante as atividades, notou-se que as crianças interagiram com os jogos digitais, sendo desafiadas e motivadas a buscar novas respostas, solicitando ajuda da mediadora, que por sua vez, observava e interagia com o jogo e com a criança, por meio de perguntas, dicas e feedback. Para Vygotsky (2009), a mediação é o processo de intervenção de um elemento numa interação fazendo com que ela deixe de ser direta e se torne mediada. Segundo Oliveira (1998, p. 27), a “[ ...] presença de elementos mediadores introduz um elo a mais nas relações organismo/meio, tornando-as mais complexas. Ao longo do desenvolvimento do indivíduo, as relações mediadas passam a predominar sobre as relações diretas [...]". Assim, observou-se que o uso da mediação possibilitou à criança expressar as diversas formas de comunicação identificadas nesta investigação.

Não obstante a relevância das atividades e dos procedimentos, a atuação do mediador é de fundamental importância para a intervenção com os jogos digitais e com as crianças. O mediador deve respeitar o tempo de resposta de cada indivíduo e estar preparado do ponto de vista profissional na questão da fundamentação teórica e da prática de recursos da Comunicação Alternativa e da Tecnologia Assistiva para que consigam atuar de forma mais efetiva no desenvolvimento da comu- 
nicação de crianças sem oralidade (BROWNING，2003， DELI BERATO，2009, NUNES, 2003, ZANGARI, 1994).

\section{Considerações Finais}

Os jogos digitais propiciaram às crianças com deficiências múltiplas, decorrentes de Paralisia Cerebral, e sem oralidade o uso de diferentes formas de comunicação. Esse resultado sugere a importância da Tecnologia Assistiva para as trocas comunicativas, bem como a possibilidade de utilizar tais recursos como procedimento educativo e de promoção do desenvolvimento do repertório de habilidades sociais dessas crianças.

Considerando as limitações do presente estudo, novas pesquisas poderiam: (a) ampliar a amostra; (b) realizar mais sessões para a mediação e, consequentemente, para a análise da comunicação; (c) analisar a diferença da ampliação da comunicação em atividades lúdicas com e sem os recursos dos jogos digitais. Além disso, futuros estudos poderiam empregar os jogos digitais como proposta de novas intervenções para o desenvolvimento da comunicação de crianças sem oralidade, testando assim a efetividade do programa.

\section{Referências}

AGUIAR, A.A.R. et al. Método JT na Educação Especial: resultados de um programa de habilidades sociais- comunicativas com deficientes mentais. Revista Educação Especial, Santa Maria, v. 23, n. 37, p. 241-256, 2010.

ALMEIDA, M.A.; PIZA, M.H.M.; LAMÔNICA, D.A.C. Adaptation of the picture exchange communication system in a school context. Pró-Fono: revista de atualização científica, Barueri, v. 17, n. 2, p. 233-240, 2005.

AMARAL-LAUAND, G.B.; MENDES, E.G. Tecnologia Assistiva: uma proposta de caracterização e classificação. In: ALMEIDA, M.A.; MENDES, E.G.; HAYASHI, M.C.P.I. (Org.). Temas em Educação Especial: múltiplos olhares. Araraquara: Junqueira \& Marin; Brasília: CAPES - PROESP, 2008. P. 392-402.

ASSOCIAÇÃO BRASILEIRA DE EMPRESAS DE PESQUISA. Critério de Classificação Econômica Brasil. São Paulo: Autor, 2003.

BERSCH, R. Tecnologia Assistiva: recursos e serviços. In: DELIBERATO, D.; GONÇALVES, M.J.; MACEDO, E.C. (Org. ). Comunicação Alternativa: teoria, prática, tecnologias e pesquisa. São Paulo: Memnon Ed. Científicas, 2009. P. 181-187. 
BROWNING, N. A Aplicação da Tecnologia Assistiva na Área de Comunicação Alternativa. In: NUNES, L.R.O.P. (Org.). Favorecendo o Desenvolvimento da Comunicação em Crianças e J ovens com Necessidades Educacionais Especiais. Rio de Janeiro: Dunya, 2003. P. 235-250.

DEL PRETTE, A; DEL PRETTE, Z.A.P. Psicologia das Relações Interpessoais: vivências para o trabalho em grupo. Rio de Janeiro: Vozes, 2001.

DELIBERATO, D. Uso de Expressões Orais Durante a Implementação do Recurso de Comunicação Suplementar e Alternativa. Revista Brasileira de Educação Especial, Marília, v. 15, n. 3, p. 369-388, 2009.

DELIBERATO, D.; GONÇALVES, M.J.; MACEDO, E.C. (Org.). Comunicação Alternativa: teoria, prática, tecnologias e pesquisa. São Paulo: Memnon Ed. Científicas, 2009.

DIRECTFB. [S.I., 2011]. Disponível em: <http://directfb.org/> Acesso em: 28 jan. 2011.

FERM, U.; AHLSÉN, E.; BJ ORCK-AKESSON, E. Conversational topics between a child with complex communication needs and her caregiver at mealtime. Augmentative and Alternative Communication, Washington, v. 20 , n. 1, p. 19-40, 2005.

HUIZINGA, J. Homo Ludens: o jogo como elemento da cultura. São Paulo: Perspectiva, 2001.

MCLEAN, L.K.; BRADY, N.C.; MCLEAN, J.E. Reported communication abilities of individuals with severe mental retardation. American J ournal of Mental Retardation, Washington, v. 100, p. 580-591, 1996.

NUNES, L.R. Linguagem e Comunicação Alternativa: uma introdução. In: NUNES, L.R. Favorecendo o Desenvolvimento da Comunicação em Crianças e Jovens com Necessidades Educacionais Especiais. Rio de Janeiro: Dunya, 2003. P. 1-13.

OLIVEIRA, M.K. Vygotsky Aprendizado e Desenvolvimento: um processo sócio-histórico. São Paulo: Scipione, 1998.

SAMESHIMA, F.S. Habilidades Expressivas de um Grupo de Alunos não Falantes Durante Atividades de Jogos. 2006. Dissertação (Mestrado em Educação) - Programa de Pós-Graduação em Educação, Universidade Estadual Paulista, 2006, Marília, BR-SP.

SAMESHIMA, F.S.; DELIBERATO, D. Habilidades Expressivas de um Grupo de Alunos com Paralisia Cerebral na Atividade de Jogo. Revista da Sociedade Brasileira de Fonoaudiologia, São Paulo, v. 14, n. 2, p. 219224, 2009. 
VYGOTSKY, L.S. A Formação Social da Mente. Trad. José Cippolla Neto Etalii. São Paulo: Martins Fontes, 1984.

VYGOTSKY, L.S. A Formação Social da Mente. São Paulo: Martins Fontes, 2009.

WALTER, C.C.F. A Aplicação do Programa de Comunicação Alternativa e Ampliada no Contexto Familiar de Pessoas com Autismo. 2006. Tese (Doutorado em Educação Especial) - Programa de Pós-Graduação em Educação Especial, Universidade Federal de São Carlos, 2006, São Carlos, BR-SP.

ZANGARI, C. Changes in speech behavior by children receiving AAC service. I nternational Society for Augmentative and Alternative Communication, Washington, v. 10, n. 1, p. 27-59, 1994.

\section{Maria I nês J esus Ferreira}

Pedagoga,mestranda em Modelagem Computacional e Tecnologia Industrial pela Faculdade de Tecnologia SENAI CIMATEC, Salvador/BA, Brasil. E-mail: inesmf23@gmail.com.

\section{Camila de Sousa Pereira-Guizzo}

Professora da Faculdade de Tecnologia SENAI CIMATEC, Salvador/BA, Brasil. E-mail: camila.pereira@fieb.org.br.

\section{Xisto Lucas Travassos}

Professor da Faculdade de Tecnologia SENAI CIMATEC, Salvador/BA, Brasil. E-mail: lucas.travassos@fieb.org.br

\section{Lynn Rosalina Gama Alves}

Professora da Faculdade de Tecnologia SENAI CIMATEC, Salvador/BA, Brasil. E-mail: Iynn.alves@fieb.org.br

\section{Renelson Ribeiro Sampaio}

Professor da Faculdade de Tecnologia SENAI CIMATEC, Salvador/BA, Brasil. E-mail: renelson.sampaio@fieb.org.br 